\title{
Browsing herbivores improve the state and functioning of savannas: a model assessment of alternative land use strategies
}

\author{
Katja Irob ${ }^{1}$, Niels Blaum ${ }^{2}$, Selina Baldauf ${ }^{1}$, Leon Kerger $^{1}$, Angelina Kanduvarisa ${ }^{3}$, Ben \\ Strohbach $^{3}$, Dirk Lohmann ${ }^{2}$, and Britta Tietjen ${ }^{1}$ \\ ${ }^{1}$ Freie Universität Berlin Fachbereich Biologie Chemie Pharmazie \\ ${ }^{2}$ University of Potsdam \\ ${ }^{3}$ Namibia University of Science and Technology
}

July 21,2021

\begin{abstract}
Changing climatic conditions and unsustainable land use are perceived as major threats to savannas worldwide. In the past, land use in African savannas was dominated by livestock-farming as one of the major economic products, which led to degraded, shrub encroached pastures in many regions. One response to this widespread degradation is a shift from land use dominated by cattle to strategies characterized by animal compositions with more mixed feeding regimes and higher browser proportions. However, the consequences for ecosystem properties and processes remain so far largely unclear. We used the ecohydrological, spatially explicit savanna model EcoHyD to assess the impacts of two contrasting, herbivore-related land use strategies on a Namibian savannah: grazing versus browsing herbivores. We varied the densities of grazers and browsers and determined the resulting composition and diversity of the plant community, total vegetation cover, soil moisture and water use by plants. Our results show that properties making plants less attractive to herbivores were best adapted to different densities of grazing (cattle) or browsing (pure browsing wildlife) animals. Also, properties leading to a competitive advantage under limited water availability were among the dominant ones. Overall, the results are in line with our expectations: we found heavy shrub encroachment with a loss of the perennial grass matrix under high stocking rates of cattle. A novel and unexpected result was that regardless of the density of browsers, grass cover and plant functional diversity were significantly higher in wildlife scenarios. This increased grass cover, but also the higher total cover improved water uptake by plants. We conclude that in contrast to grazers, browsers even in high densities do not lead to ecosystem degradation, but rather sustain a diverse vegetation with high cover of perennial grasses over a long time, implying also a lower erosion risk and higher provision of ecosystem services.
\end{abstract}

\section{Hosted file}

Irob_et_al_2021.docx available at https://authorea.com/users/426705/articles/531129-

browsing-herbivores-improve-the-state-and-functioning-of-savannas-a-model-assessment-

of-alternative-land-use-strategies 

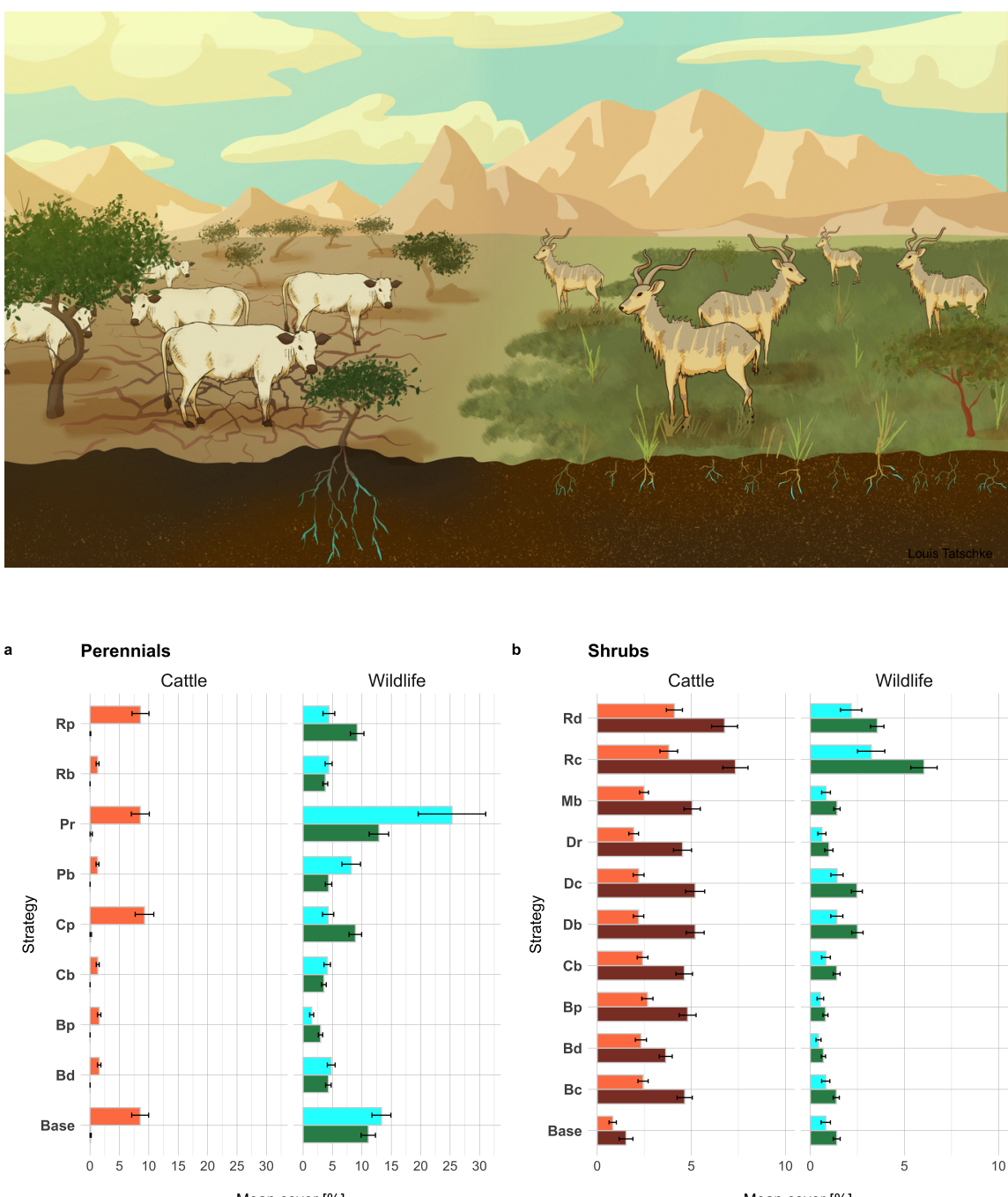

b Shrubs

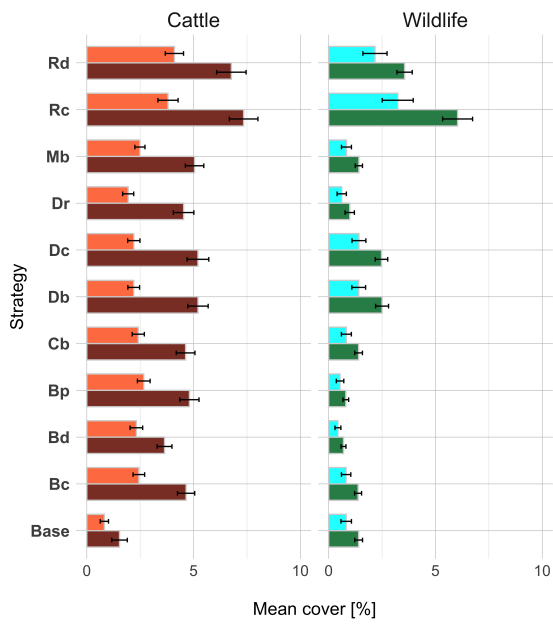

Cattle low Wildlife low $\square$ Cattle high $\square$ Wildlife high

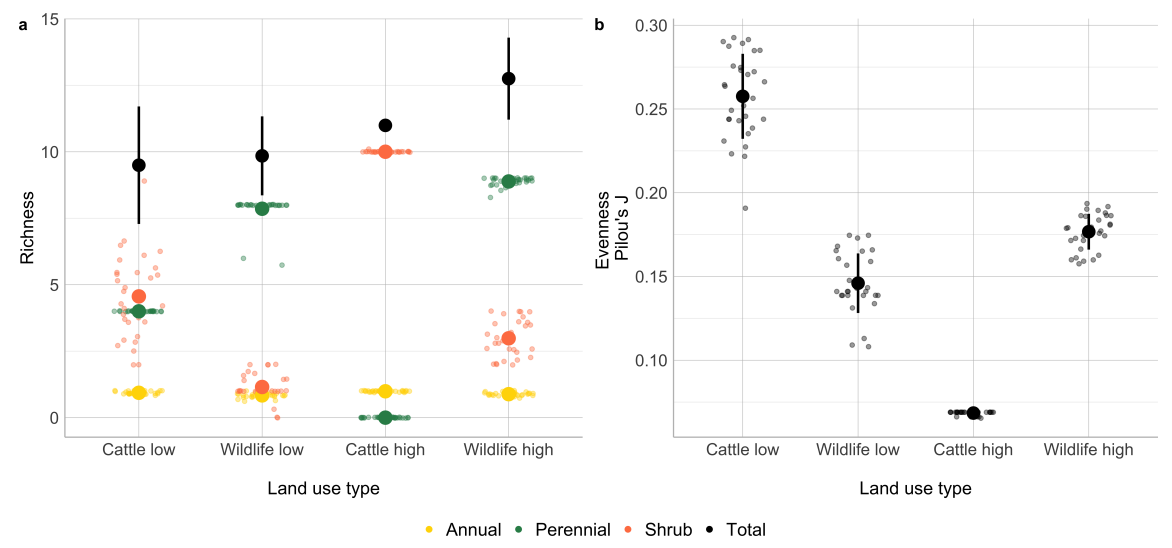



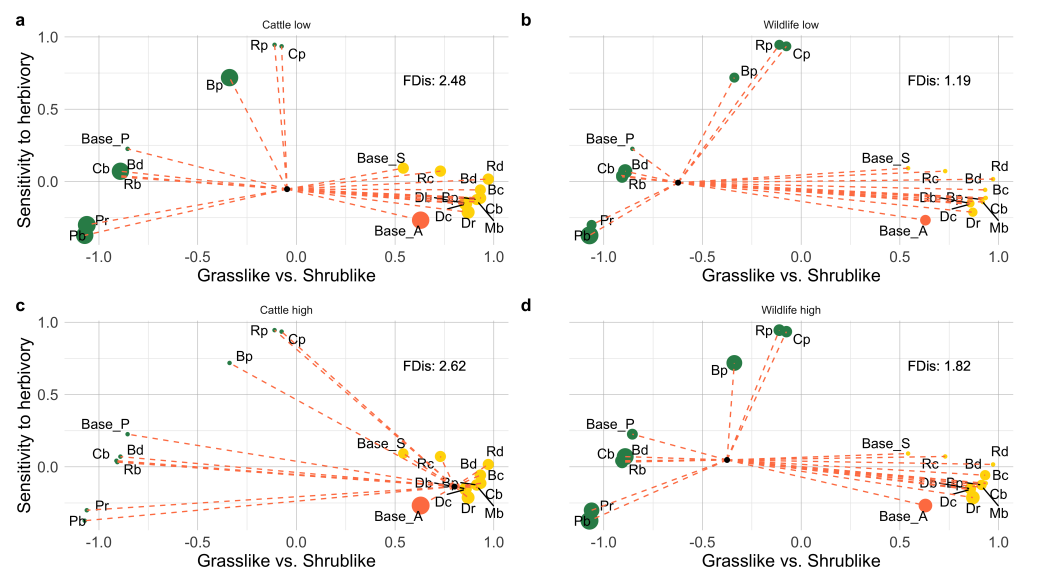

PFT

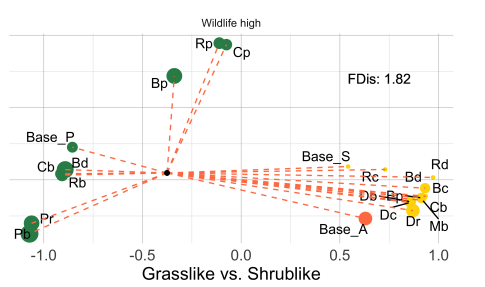

abundance

- 0

- 5

$\stackrel{-10}{15}$

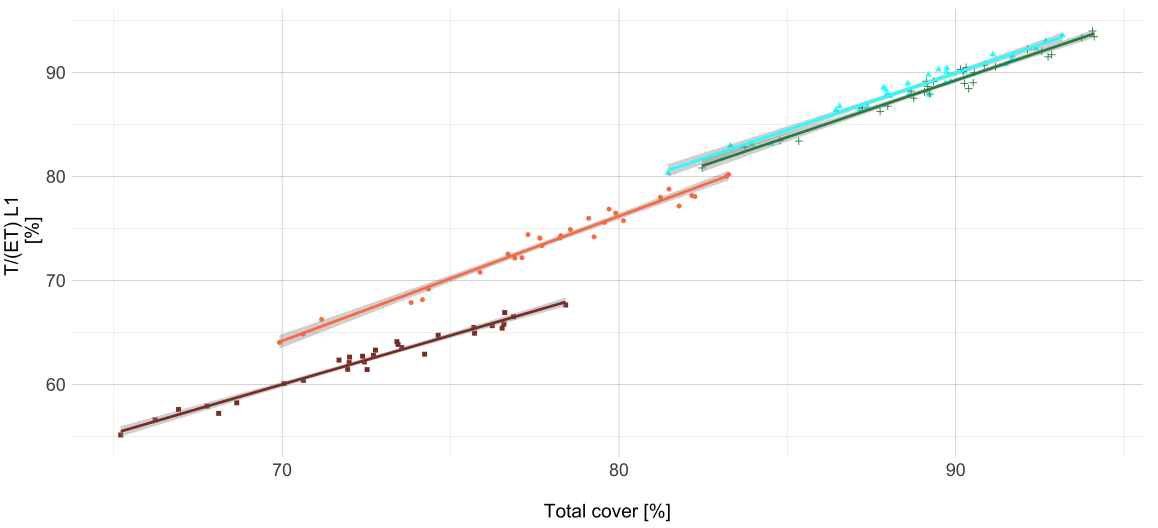

- Cattle low - Wildlife low - Cattle high - Wildlife high 